\title{
Experiential Learning Curriculum Delivery Approach for Quality Improvement in Resource Limited Settings: Mobile Learning for Point-of-Care Technologies
}

\author{
Nkosinothando Chamane ${ }^{1} \&$ Tivani Phosa Mashamba-Thompson ${ }^{1}$ \\ ${ }^{1}$ Department of Public Health Medicine, School of Nursing and Public Health, University of KwaZulu-Natal, \\ Durban, South Africa \\ Correspondence: Nkosinothando Chamane, Department of Public Health Medicine, School of Nursing and Public \\ Health, University of KwaZulu-Natal, Durban, South Africa. E-mail: thandocharmane@yahoo.com
}

Received: August 7, 2019 Accepted: September 9, 2019 Online Published: November 30, 2019

doi:10.5539/gjhs.v11n13p158 URL: https://doi.org/10.5539/gjhs.v11n13p158

\begin{abstract}
Background: Despite impressive progress that has been made in the provision of health care services to all, the issue of quality service delivery still remains a challenge particularly for point-of-care (POC) diagnostics in resource-limited-settings. Poor competency of primary health care workers in these settings has been shown to be amongst the main contributors to poor quality service delivery.

Findings: Participatory-based continuous professional development (CPD) strategies to support technology advancements in health care are recommended. Experiential learning approaches have been shown to be efficient in supplementing traditional teaching methods for both health care students and professionals. These approaches have been shown to further contribute towards continuous skills development and lifelong learning.

Conclusion: This review therefore provided an overview of literature on experiential learning as one of CPD approaches in relation to health care service improvement in resource-limited setting. In addition, this review has recommended a mobile-based experiential learning approach to help deliver a quality POC technology curriculum to Primary health care-based workers in resource-limited settings.
\end{abstract}

Keywords: primary health care, quality improvement, experiential learning, onsite training, participatory-based learning and mobile learning

\section{Introduction}

With continuous advances in technologies for prevention and treatment of HIV and TB, continuous professional development (CPD) of health care workers (HCWs) remains a high priority especially, in countries with a dual burden of TB/HIV epidemics (Feldacker et al., 2017; Wirtz et al., 2016). The World Health Organisation (WHO) recommends training and competency assessments for personnel, including initial and follow up trainings as components of a quality management system (QMS) necessary for provision of quality POC diagnostic services (Jaya, Drain, \& Mashamba-Thompson, 2017). Studies have been conducted to evaluate compliance to the QMS in LMIC, specifically on HIV and TB testing in South Africa (Jaya et al., 2017; Mwisongo, Peltzer, Mohlabane, \& Tutshana, 2016). These studies highlighted knowledge gaps and barriers to the provision of quality services in resource limited settings, which include challenges concerning test user perspectives and competency(Jaya et al., 2017; Mwisongo et al., 2016). Inclusion of a compulsory system has shown improvement in the quality of services provided to patients in resource limited settings (French \& Dowds, 2008; Martin, Labadarios, Marals, \& Wentzel-Viljoen, 2008). Using participatory based approaches like experiential learning was found to strengthen community research partnerships as well as provide valuable training experiences for current and aspiring health professionals, where participatory based learning can be defined as learning centred on the active participation of persons involved (Marriot, Lipus, et al., 2015). Context and topic specific CPD programs are also recommended for improved service delivery (Feldacker et al., 2017). Experiential learning is a theory of learning simply defined as learning achieved through the appropriate use of participants' experiences (Allodola, 2014).It has been shown to be a successful intervention which can afford PHC workers in resource-limited setting opportunities of CPD they are limited from (A. Kolb \& D. Kolb, 2009; Yardley, Teunissen, \& Dornan, 2012).

The purpose of this review is to provide an overview of literature on experiential learning as one of CPD 
approaches in relation to health care service improvement in resource-limited settings. In this study, we define resource-limited settings as remote areas, where there is poor infrastructure only limited to the provision of basic health care and where access to continuous training and development of workers is limited. We present literature on the definition of experiential learning from different contexts, the utility of experiential learning approaches for PHC workers, efficiency of experiential learning approaches on PHC workers and the acceptability of experiential learning for PHC-based workers in resource-limited settings. In addition, we propose incorporation of mobile learning to help improve the quality of POC technologies at PHC clinics in resource-limited settings. To retrieve relevant literature used in this review, an electronic search was conducted using advanced search from the university library services in the following databases: PubMed, Google Scholar, Ebscohost (Academic search complete, ERIC, Nursing reference centre, HealthStream and EBSCO Health). The following search terms were used: Primary health care, quality improvement, experiential learning, onsite training, participatory-based learning and mobile learning.

\section{Defining Experiential Learning}

Many definitions of experiential learning can be found in literature globally, but in its simplest form experiential learning is defined as learning achieved through the appropriate use of current experience (Allodola, 2014). It is also defined as the construction of knowledge and meaning from real-life experience (Yardley et al., 2012). Majority of studies conducted in Upper-middle-income countries UMICs, including those conducted within the last five years (de Oliveira et al., 2015; Dhital et al., 2015) refer back to Kolb (1984) four-stage experiential learning cycle: Concrete Experience, Reflective Observation, Abstract Conceptualization and Active Experimentation to define experiential learning. The Experiential Learning Theory (ELT) provides a holistic model of the learning process and a multi-linear model of professional development, both of which are consistent with what is known about how people learn, and develop (Boyatzis \& Kolb, 2003). The concept to learn with and from one another, implies an educational strategy that is process driven and experiential in approach. Developmental quality exists to this strategy since it relies a lot on learning by doing (Becker, Walton-Moss, \& Hanyok, 2015).

The Experiential learning theory principles have been shown to overlap with those of various teaching and learning theories in health professional education. These include problem-based learning (PBL), adult education, inter-professional education and transformative/emancipatory learning(Gewurtz, Coman, Dhillon, Jung, \& Solomon, 2016). What sets experiential learning apart is that it draws heavily on Kolb's work which conceptualizes experience as the foundation and stimulus for continuous cycles of learning, which can be adapted to various contexts as illustrated in Figure 1 below (Allodola, 2014; Gewurtz et al., 2016; Poore, Cullen, \& Schaar, 2014).

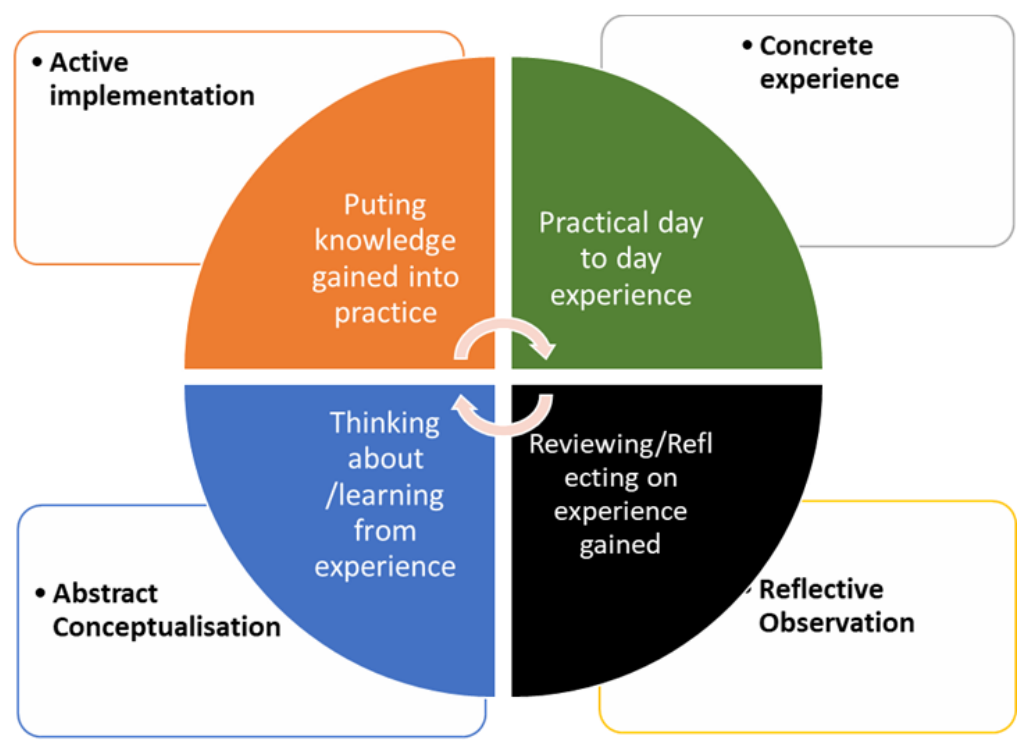

Source: adapted from Kolb \& Kolb of 2003 Experiential Learning Theory: Previous Research and New Directions (Boyatzis \& Kolb, 2003)

Figure 1. Continuous learning and development through Kolb experiential learning cycle 


\section{The Utility of Experiential Learning Approaches for PHC Workers}

In this study, we have defined utility of experiential learning in terms of its application to training and development of PHC workers. In high income countries (HICs) experiential learning has been utilised a lot in medical education in two ways. (i) Through experiences which have been included in a curriculum design to bring the learner into contact with a predetermined role and context and (ii) through experience gained in authentic workplaces that are concurrently involved in education and delivering real-life services (Allodola, 2014; Yardley et al., 2012). Few studies have presented evidence on the application of experiential learning for training of PHC professionals especially nurses and councillors (Marriot et al., 2015; McDonald, Jackson, Wilkes, \& Vickers, 2012). These include a case study on nurses and midwives revealed that there was limited research on work-based interventions that provide opportunities for clinical nurses to take time away from their challenging work environments and focus on elements that could improve their experiences of work (McDonald et al., 2012). A study conducted in Portland found that engaging community members in health research can help cultivate effective partnerships while providing experiential learning and continuing education opportunities for current and aspiring health personnel (Marriot et al., 2015).

In resource-limited settings, experiential learning is mostly used in the training of student nurses, public health practitioners, and medical students. The following experiential learning approaches were shown to form part of the healthcare students training: clinical simulations (de Oliveira et al., 2015), field studies (Hu, Abraham, Mitra, \& Griffiths, 2015) and public health screenings (PHS) (Wee, Yeo, Tay, Lee, \& Koh, 2010). The proposal and implementation of experiential learning through clinical simulation with undergraduate nursing students proved to be a rich and appropriate process of training students to develop creative and critical-reflexive skills (de Oliveira et al., 2015). A study conducted in Bangladesh showed that field studies provided students with first-hand insights into issues such as delivery of primary care services, the impact of environmental conditions and poverty on a large scale, and the challenges associated with a rapidly developing economy (Hu et al., 2015). In South Africa experiential learning has also been utilised to provide practical experiences for medical students (Prose, Diab, \& Matthews, 2013). Another study successfully employed the reflection step of experiential learning to explore the work experiences of PHC clinic nursing managers through the use of reflective diaries (Munyewende \& Rispel, 2014). Limited research on the utility of experiential learning as an approach to train on the job professionals was found. This demonstrates a gap in research aimed at determining the implementation of experiential learning approaches on PHC-based workers. Hence, participatory based approaches have been recommended for continuous training of PHC workers in resource limited settings (Allodola, 2014; Liikanen \& Lehto, 2013; Marriot et al., 2015; McDonald et al., 2012).

Most research both globally and locally focused on the outcomes of experiential learning, and minimal research has been done to demonstrate each step in the process, particularly in resource limited settings (Dhital et al., 2015). The findings of studies conducted in UMICs including China, Brazil and South Africa concerning experiential learning approaches' effectiveness in medical education are consistent with those of studies conducted in higher income countries $(8,17,28)$.

\section{The Efficiency of Experiential Learning Approaches on PHC Workers}

The efficiency of experiential learning has been defined in terms of its ability to add value to the competency of PHC workers as well as to the improvement of services provided in the PHC clinics. The goal of experiential learning has been shown mainly to be to expose students to a practice that enhances the knowledge of subject matter, as well as the culture of that particular community (Pagano \& Roselle, 2009; Yardley et al., 2012). Experiential learning through a participatory-based approach was shown to provide valuable training experiences for current and aspiring health practitioners (Marriot et al., 2015). In a study conducted in Germany involving nursing graduate students in experiential outreach activities (D'Lugoff \& McCarter, 2005), the participants voiced that the opportunities provided were consistent with their course work, adding a valuable and supplemental practice component (D'Lugoff \& McCarter, 2005). An international systematic review study also showed that educational outreach programs are effective, however they can be very time consuming and expensive (Allodola, 2014). Globally, studies involving PHC health professionals demonstrated the reflection step of experiential learning to be significantly efficient $(9-10,28)$. Reflection is defined as a tool to help take a careful inventory of events or situations (Pagano \& Roselle, 2009). This step was shown to contribute to the identification of root causes of health systems inefficiencies, to curriculum improvement and to informing of future policies and courses $(9,11)$.

Research revealed experiential learning approaches to be more efficient when used as a supplementary approach (de Oliveira et al., 2015; Wee et al., 2010). Wee et al. (2010) found their experiential learning project to be less 
effective in teaching clinical procedures and therefore, recommended that this learning approach should supplement and not replace traditional pedagogical methods of PHC health care teaching and training (Wee et al., 2010). De' Oliveira et al., 2015 also argued that simulated practice and/or experiential learning do not replace real context, but enrich learning and offers students the opportunity to perceive patients as unique individuals with personal ways of dealing with diseases (de Oliveira et al., 2015). Experiential learning was shown to be best efficient when used as a tool of giving students an opportunity to acquire valuable skills that are not easily taught in a lecture-based setting (de Oliveira et al., 2015; Wee et al., 2010).

In South Africa research showed that the experiential learning experiences provided to the medical students had a powerful impact on their ability to interact with people from different cultural backgrounds. They gained more understanding of the people they were serving and could thus serve them better in the future (Prose et al., 2013). In another local study the reflection step of experiential learning was employed to explore the work experiences of PHC clinic nursing managers through the use of reflective diaries. The outcomes included the identification of root causes to some of the health system inefficiencies and a recommendation for policy-makers to address these in a participatory manner was made (Munyewende \& Rispel, 2014).

\section{Acceptability of Experiential Learning for PHC-Based Workers}

In this study, the acceptability of experiential learning is defined in terms of the program's contribution to CPD and lifelong learning. CDP is an integral part of lifelong learning. In discussing these two concepts, there are two elements of experiential learning to be considered. Firstly, it is necessary for persons to recognise what is common between new experiences and previous experiences. Secondly, they need to be able to identify why these experiences are different. In this way they will begin to learn how to recognise circumstances which call for them to judge how to translate or refine learning to meet a new challenge and thus enable extension of their existing knowledge (Yardley et al., 2012).

In HICs including the Netherlands and the UK experiential learning was shown to be acceptable mostly in medical education as a model to provide practical experiences to medical students relevant to their future areas of work (Yardley et al., 2012). It was also shown to provide CPD opportunities to medical practitioners already in the field (Boyatzis \& Kolb, 2003; Prose et al., 2013; Yardley et al., 2012). In a systematic review study on the training of nurses in POC testing conducted in four HICs, it was found that nurses in different healthcare settings can be trained using various methods, which include self-learning through video tapes, workshops, distance learning and experiential learning (Liikanen \& Lehto, 2013). However where training was delivered with the support of laboratory professionals, nurses were found to perform good-quality POC testing (Liikanen \& Lehto, 2013).

In resource limited settings within the UMICs, experiential learning through various approaches such as clinical simulations and Public health screenings was shown to enable active search for knowledge. This further awakens critical thinking and promotes reflection as well as contribute to the student's overall development throughout life (de Oliveira et al., 2015). This enabled students to acquire leadership skills and the ability to take action as they continued with service delivery (Wee et al., 2010). Like in HICs, experiential learning was shown to be acceptable largely in medical education (Dhital et al., 2015; Prose et al., 2013).

\section{The Need for Use of Experiential Learning for Quality Improvement of Point-of-Care (POC) Technologies at Primary Healthcare}

POC technologies consist of the devices and systems that support health care professionals in their daily activities, which include caring for patients, monitoring, and recording of their health progress. Examples of common POC technologies include the electronic medical record keeping (EMR), POC information technology and POC testing (Addondata, 2017). In this review our main focus is POC diagnostics in resource limited settings, where Paper-based assays such as lateral flow strips and dipsticks (Uni-GoldRecombigenHIVtest, DetermineHIV-1/2 $\mathrm{Ag} / \mathrm{Ab}$ Combo and INSTI HIV-1 Rapid Antibody) are the most widely used (T. Mashamba-Thompson, Jama, Sartorius, Drain, \& Thompson, 2017; Wang et al., 2016). These were shown to be the most widely used because of their simple working procedure and low cost (Wang et al., 2016). Technological complexity as required by the assay working mechanism has been shown to contribute as the main barrier for developing POC diagnostics. For this type of testing to be efficient in any health care institution, it needs to go through the following procedures: i) sample collection, ii) sample processing, iii) testing and/or instrumentation, iv) analysis of results and reporting, v) interpretation and vi) waste disposal. These multiple testing procedures, pose great technical challenges for POC testing in resource limited settings, because of limited laboratory testing capability and lack of skilled operators (Kuupiel, Bawontuo, \& Mashamba-Thompson, 2017; Wang et al., 2016).

POC testing technologies such as those mentioned above can be used to improve health outcomes of patients in 
resource-limited settings as they eliminate the need for laboratory infrastructure, allowing for non-laboratory users to perform diagnostic tests (N. Pai, Vadnais, Denkinger, Engel, \& M. Pai, 2012). However this leaves room for errors and can compromise the quality of services provided. Studies on the reliability of HIV rapid tests found that the reliability of the POC diagnostics services delivered is affected by the user of the test (Moodley, Moodley, \& Ndabandaba, 2008; Yeo, Ngo, Ng, Lim, \& Jacob, 2011). The lack of training of personnel performing POC diagnostic tests was highlighted as one of the limitations in HIV rapid testing in resource limited settings (Gray et al., 2007). Researchers in applications of POC diagnostics argue that the mere availability of rapid tests does not automatically ensure their proper adoption $(1,5)$. There is therefore a need for interventions that would provide PHC workers with practical on-site training and development opportunities, such as experiential learning based frameworks.

\section{Discussion}

The findings of the review show that experiential learning approaches have been utilised in various projects, with higher education students as participants. Although experiential education emerged as a recognised field of education since the 1970s (Hammerman, Hammerman, \& Hammerman, 2007), a limited number of studies reported evidence of experiential learning with PHC professionals as participants in UMICs. Experiential learning was shown to be efficient in providing students with real time experiences on the delivery of quality primary care services, however there was no evidence of the continuation of these strategies to the professional level in resource limited settings. The efficiency of the reflection step of experiential learning in helping to identify root courses to health care inefficiencies as well as its contribution to the development of new polices and course material is a critical and necessary aspect to be considered for institutional continuous development. In comparison to other traditional models of learning for PHC workers, experiential learning was shown to be more efficient when used as a support strategy. However, it was shown to be less effective in teaching carrying out of clinical procedures. It was therefore recommended as an intervention to supplement and not replace traditional pedagogical methods of teaching and learning in PHC (de Oliveira et al., 2015; Wee et al., 2010). Experiential learning approaches were shown to be acceptable to nursing, public health, and medical students for continuous skills development and lifelong learning (de Oliveira et al., 2015; Hu et al., 2015; Wee et al., 2010). However in resource-limited settings, there was no evidence of follow up strategies to ensure continuous development as the students' progress to the work environment. Considering the quality requirements of continuous improvement, this may be considered as a non-conformance and a call for collaborations between higher education and PHC institutions.

There is limited evidence of research aimed at investigating the impact of experiential learning approaches on quality service delivery of POC diagnostics. Bearing in mind that nurses are the main custodians of PHC, this finding is a concern and a limitation in research. Primary studies reporting on the step by step implementation of experiential learning processes, particularly focusing on POC diagnostics are very limited, but were recommended by researchers in POC diagnostics as well as in CPD (Feldacker et al., 2017; T. P. Mashamba-Thompson, Sartorius, Stevens, \& Drain, 2016). Moreover, it has been shown that technology alone does not define a POC diagnostic test. It is rather the successful use of the POC technology that defines a diagnostic process as POC diagnostic testing (N. P. Pai, Vadnais, Denkinger, Engel, \& Pai, 2012). This emphasises the need to develop and empower the primary custodians of PHC.

With the continuous upscaling in the provision of mobile POC diagnostic kits, as well as the enabling power provided by Mobile health (m-health) interventions, resource limitations can no longer be an excuse. Mobile health (m-health) interventions including POC diagnostic kits and m-learning programs have been shown to have enormous potential to improve accessibility to quality health services provided in resource limited settings (Cao et al., 2016). We therefor propose a mobile-based experiential learning approach, which encoporates mobile learning (m-learning) to help deliver a quality POC technology curriculum to PHC-based workers in resource-limited settings. M-learning is defined as any form of learning mediated through a mobile device (Klimova \& Poulová, 2016; Rajasingham, 2011). One of the major benefits of m-learning is that it can reach people in remote areas, where access to training and development facilities is limited (Ally, 2009). In the proposed approach, content will be delivered through an application than can be downloaded on a cell phone, laptop or a PC readily accessible to nurses and counsillors performing POC diagnostics. The application will be optimised by the use of video segments as well as discussion forums to enable "learners" give feedback continuously as illustrated in Table 1 below. 
Table 1. Objectives for a point-of-care diagnostics m-learning based experiential-learning training programme for primary healthcare workers.

\section{Learning outcomes guided by \\ Kolb (2001) experiential Experiential learning objective Intended learning outcome \\ learning theory(13)}

\begin{tabular}{lll}
\hline Concrete experience (25\%) & $\begin{array}{l}\text { Watch and critique a short video } \\
\text { clip of an incorrect administration } \\
\text { of a POC-diagnosis. }\end{array}$ & $\begin{array}{l}\text { To establish the nurses prior knowledge, experience } \\
\text { and ability to recognise incorrect practice. }\end{array}$ \\
\hline Reflection (25\%) & $\begin{array}{l}\text { Provide content on policies and } \\
\text { principles for POC diagnostics } \\
\text { services quality assurance. }\end{array}$ & $\begin{array}{l}\text { Nurses to read the content and reflect on the } \\
\text { practices shown in the video, with reference to } \\
\text { policies and guiedlines. Then give feedback in a } \\
\text { Discussion forum. }\end{array}$ \\
\hline Abstract conceptualisation (20\%) & $\begin{array}{l}\text { Meditate on the feedback given and } \\
\text { knowledge gained }\end{array}$ & $\begin{array}{l}\text { Utilise the knowledge gained to prepare for their } \\
\text { own practice }\end{array}$ \\
\hline Implementation (30\%) & $\begin{array}{l}\text { Perform individual POC testing, } \\
\text { record and share videos. }\end{array}$ & Provide constructive feedback. \\
\hline & $\begin{array}{l}\text { Watch and assess each other's } \\
\text { performances on the group. }\end{array}$ & $\begin{array}{l}\text { Choose one video deemed as the best, to be } \\
\text { continuously refined and used as a model teaching } \\
\text { tool. }\end{array}$ \\
\hline
\end{tabular}

Due to the ever changing nature of health care services as well as continuous advances in POC technologies, implementation of specific experiential learning strategies alone cannot guarantee indefinite CPD or quality service delivery (T. P. Mashamba-Thompson et al., 2016). This strategy will therefore require complementary strategies including monitoring and evaluation through scheduled audits utilising audit tools for online education interventions adapted from the quality guidelines for online courses (Herrington, Herrington, Oliver, Stoney, \& Willis, 2001). Procedural guidance for practice settings and device training and maintenance services within the institutions have also been suggested to combat barriers associated with independent use of m-learning in higher education institutions (Lall et al., 2019). In a systematic review on the influences of m-learning implementation for medical and nursing education, experiential or ongoing training and local technical support were particularly highlighted as the most valued by the participants (Lall et al., 2019). These are highly recommended to support practice in resource-limited-settings.

\section{Conclusion}

This study provided evidence that experiential learning approaches were useful and efficient in providing practical experiences to supplement traditional training models. Moreover they have the potential to provide CPD opportunities to PHC workers in resource-limited-settings. Experiential learning research on PHC professionals is limited as majority of available literature consisted of undergraduate students as participants. Participatory-based learning models for PHC works were recommended by a significant number of studies both locally and internationally. We recommend an experiential m-learning curriculum for point-of-care diagnostics training of PHC workers to improve the proficiency of PHC workers as well as the quality of POC diagnostic services they provide. This will further contribute towards the improvement of health comes in resource-limited-settings.

\section{Competing Interests Statement}

The authors declare that there are no competing or potential conflicts of interest.

\section{References}

Addondata.

what-is-point-of-care-poc-technology.

Retrieved

from https://www.addondata.com/2017/10/what-is-point-of-care-poc-technology/

Allodola, V. F. (2014). The effects of educational models based on experiential learning in Medical Education: an international literature review. Tutor, 14(4), 23-49. https://doi.org/10.14601/Tutor-14725

Ally, M. (2009). Mobile Learning: Transforming the Delivery of Education and Training.

Becker, K., Walton-Moss, B., \& Hanyok, L. A. (2015). Creating your ideal primary care practice: innovative interprofessional learning activity. $J$ Nurs Educ, 54(5), 300. https://doi.org/10.3928/01484834-20150417-11 
Boyatzis, R., \& Kolb, D. (2003). Experiential learning theory bibliography (23, 1-40). Cleveland, OH: Experience Based Learning Systems Inc.

Cao, Y., Liu, C., Liu, B., Brunette, M. J., Zhang, N., Sun, T., . . Garcia, L. L. (2016). Improving tuberculosis diagnostics using deep learning and mobile health technologies among resource-poor and marginalized communities. Paper presented at the 2016 IEEE First International Conference on Connected Health: Applications, Systems and Engineering Technologies (CHASE). https://doi.org/10.1109/CHASE.2016.18

D'Lugoff, M. I., \& McCarter, J. (2005). Learning from experience: three community health population-based outreach projects for graduate and undergraduate students. Int J Nurs Educ Scholarsh, 2, Article 17. https://doi.org/10.2202/1548-923X.1130

de Oliveira, S. N., do Prado, M. L., Kempfer, S. S., Martini, J. G., Caravaca-Morera, J. A., \& Bernardi, M. C. (2015). Experiential learning in nursing consultation education via clinical simulation with actors: Action research. Nurse Educ Today, 35(2), e50-e54. https://doi.org/10.1016/j.nedt.2014.12.016

Dhital, R., Subedi, M., Prasai, N., Shrestha, K., Malla, M., \& Upadhyay, S. (2015). Learning from Primary Health Care Centers in Nepal: reflective writings on experiential learning of third year Nepalese medical students. BMC Res Notes, 8, 741-741. https://doi.org/10.1186/s13104-015-1727-2

Feldacker, C., Pintye, J., Jacob, S., Chung, M. H., Middleton, L., Iliffe, J., \& Kim, H. N. (2017). Continuing professional development for medical, nursing, and midwifery cadres in Malawi, Tanzania and South Africa: A qualitative evaluation. PloS one, 12(10), e0186074. https://doi.org/10.1371/journal.pone.0186074

French, H., \& Dowds, J. (2008). An overview of Continuing Professional Development in physiotherapy (Vol. 94). https://doi.org/10.1016/j.physio.2007.09.004

Gewurtz, R. E., Coman, L., Dhillon, S., Jung, B., \& Solomon, P. (2016). Problem-based learning and theories of teaching and learning in health professional education. Journal of Perspectives in Applied Academic Practice, 4(1). https://doi.org/10.14297/jpaap.v4i1.194

Gray, R. H., Makumbi, F., Serwadda, D., Lutalo, T., Nalugoda, F., Opendi, P., ... \& Wawer, M. J. (2007). Limitations of rapid HIV-1 tests during screening for trials in Uganda: diagnostic test accuracy study. Bmj, 335(7612), 188. https://doi.org/10.1136/bmj.39210.582801.BE

Hammerman, D. R., Hammerman, W. M., \& Hammerman, E. L. (2007). Teaching in the outdoors (5th ed.). Danville, IL: Interstate Publishers.

Herrington, A., Herrington, J., Oliver, R., Stoney, S., \& Willis, J. (2001). Quality guidelines for online courses: the development of an instrument to audit online units. Paper presented at the P18th Conference of the Australasian Society for Computers in Learning in Tertiary Education (pp. 263-270). Melbourne, VIC. Biomedical Multimedia.

Hu, C. X. J., Abraham, A., Mitra, A. K., \& Griffiths, S. M. (2015). The benefits of experiential learning in global public health. Public Health, 136, 196-199. https://doi.org/10.1016/j.puhe.2015.10.030

Jaya, Z., Drain, P. K., \& Mashamba-Thompson, T. P. (2017). Evaluating quality management systems for HIV rapid testing services in primary healthcare clinics in rural KwaZulu-Natal, South Africa. PLoS ONE, 12(8), e0183044. https://doi.org/10.1371/journal.pone.0183044

Klimova, B., \& Poulová, P. (2016). Mobile Learning in Higher Education (Vol. 22). https://doi.org/10.1166/asl.2016.6673

Kolb, A., \& Kolb, D. (2009). The learning way: Meta-cognitive aspects of experiential learning. Simulation \& Gaming, 40, 297-327. https://doi.org/10.1177/1046878108325713

Kuupiel, D., Bawontuo, V., \& Mashamba-Thompson, T. P. (2017). Improving the Accessibility and Efficiency of Point-of-Care Diagnostics Services in Low-and Middle-Income Countries: Lean and Agile Supply Chain Management. Diagnostics, 7(4), 58. https://doi.org/10.3390/diagnostics7040058

Lall, P., Rees, R., Law, G. C. Y., Dunleavy, G., Cotič, Ž., \& Car, J. (2019). Influences on the implementation of mobile learning for medical and nursing education: Qualitative systematic review by the Digital Health Education Collaboration. Journal of medical Internet research, 21(2), e12895. https://doi.org/10.2196/12895

Liikanen, E., \& Lehto, L. (2013). Training of nurses in point-of-care testing: a systematic review of the literature. Journal of Clinical Nursing, 22(15-16), 2244-2252. https://doi.org/10.1111/jocn.12235

Marriot, L. K., Lipus, A. C., Choate, L., Smith, J., Coppola, L., Cameron, W. E., \& Shannon, J. (2015). 
Experiential Learning Through Participatory Action Research in Public Health Supports Community-Based Training of Future Health Professionals. Pedagogy in health promotion, 1, 220-232. https://doi.org/10.1177/2373379915601119

Martin, C., Labadarios, D., Marals, D., \& Wentzel-Viljoen, E. (2008). Dietitians' perceptions of the continuing professional development system in South Africa. South African Journal of Clinical Nutrition, 21(2), 27-33. https://doi.org/10.1080/16070658.2008.11734158

Mashamba-Thompson, T., Jama, N., Sartorius, B., Drain, P., \& Thompson, R. (2017). Implementation of point-of-care diagnostics in rural primary healthcare clinics in South Africa: perspectives of key stakeholders. Diagnostics, 7(1), 3. https://doi.org/10.3390/diagnostics7010003

Mashamba-Thompson, T. P., Sartorius, B., Stevens, F. C. J., \& Drain, P. K. (2016). Experiential Bloom's Taxonomy learning framework for point-of-care diagnostics training of primary healthcare workers. Afr $J$ Lab Med, 5(1), 449. https://doi.org/10.4102/ajlm.v5i1.449

McDonald, G., Jackson, D., Wilkes, L., \& Vickers, M. H. (2012). A work-based educational intervention to support the development of personal resilience in nurses and midwives. Nurse Educ Today, 32(4), 378-384. https://doi.org/10.1016/j.nedt.2011.04.012

Moodley, D., Moodley, P., Ndabandaba, T., \& Esterhuizen, T. (2008). Reliability of HIV rapid tests is user dependent. SAMJ: South African Medical Journal, 98(9), 707-709.

Munyewende, P. O., \& Rispel, L. C. (2014). Using diaries to explore the work experiences of primary health care nursing managers in two South African provinces. Global Health Action, 7(1), 1-10. https://doi.org/10.3402/gha.v7.25323

Mwisongo, A., Peltzer, K., Mohlabane, N., \& Tutshana, B. (2016). The quality of rapid HIV testing in South Africa: an assessment of testers' compliance. African health sciences, 16(3), 646-654. https://doi.org/10.4314/ahs.v16i3.2

Pagano, M., \& Roselle, L. (2009). Beyond Reflection through an Academic Lens: Refraction and International Experiential Education. The Interdisciplinary Journal of Study Abroad, 18, 217-229.

Pai, N. P., Vadnais, C., Denkinger, C., Engel, N., \& Pai, M. (2012). Point-of-care testing for infectious diseases: diversity, complexity, and barriers in low-and middle-income countries. PLoS medicine, 9(9), e1001306. https://doi.org/10.1371/journal.pmed.1001306

Pai, N. P., Vadnais, C., Denkinger, C., Engel, N., \& Pai, M. (2012). Point-of-care testing for infectious diseases: diversity, complexity, and barriers in low-and middle-income countries. PLoS medicine, 9(9), e1001306. https://doi.org/10.1371/journal.pmed.1001306

Poore, J. A., Cullen, D. L., \& Schaar, G. L. (2014). Simulation-based interprofessional education guided by Kolb's experiential learning theory. Clinical Simulation in Nursing, 10(5), e241-e247. https://doi.org/10.1016/j.ecns.2014.01.004

Prose, N., Diab, P., \& Matthews, M. (2013). Experiential learning outside the comfort zone: Taking medical students to downtown Durban. African Journal of Health Professions Education, 5(2), 98-99. https://doi.org/10.7196/ajhpe.256

Rajasingham, L. (2011). Will mobile learning bring a paradigm shift in higher education?. Education Research International, 2011. https://doi.org/10.1155/2011/528495

Wang, S., Lifson, M. A., Inci, F., Liang, L.-G., Sheng, Y.-F., \& Demirci, U. (2016). Advances in addressing technical challenges of point-of-care diagnostics in resource-limited settings. Expert review of molecular diagnostics, 16(4), 449-459. https://doi.org/10.1586/14737159.2016.1142877

Wee, L. E., Yeo, W. X., Tay, C. M., Lee, J. J., \& Koh, G. C. (2010). The pedagogical value of a student-run community-based experiential learning project: the Yong Loo Lin School of Medicine Public Health Screening. Annals Academy of Medicine Singapore, 39(9), 686.

Wirtz, V. J., Hogerzeil, H. V., Gray, A. L., Bigdeli, M., de Joncheere, C. P., Ewen, M. A., . . Reich, M. R. (2016). Essential medicines for universal health coverage. https://doi.org/10.1016/S0140-6736(16)31599-9

Yardley, S., Teunissen, P. W., \& Dornan, T. (2012). Experiential learning: transforming theory into practice. Med Teach, 34(2), 161-164. https://doi.org/10.3109/0142159X.2012.643264

Yeo, C. P., Ngo, A., Ng, W. Y., Lim, S. H., \& Jacob, E. (2011). Assessing Performance of i-STAT at the Point of 
Care in the Emergency Room. Proceedings of Singapore Healthcare, 20(3), 157-161. https://doi.org/10.1177/201010581102000304

\section{Copyrights}

Copyright for this article is retained by the author(s), with first publication rights granted to the journal.

This is an open-access article distributed under the terms and conditions of the Creative Commons Attribution license (http://creativecommons.org/licenses/by/4.0/). 